\title{
MÉTODO CANGURU: PERCEPÇÃO MATERNA ACERCA DA VIVÊNCIA NA UNIDADE DE TERAPIA INTENSIVA NEONATAL
}

\author{
Kangaroo Care: maternal perception of the experience in the \\ neonatal intensive care unit
}

Método Madre Canguro: percepción materna de la vivencia en la unidad de cuidado intensivo neonatal

Artigo Original

\begin{abstract}
RESUMO
Objetivo: Conhecer a percepção materna acerca da vivência na primeira etapa do Método Canguru na Unidade de Terapia Intensiva Neonatal (UTIN). Métodos: Estudo descritivo, de caráter exploratório e de natureza qualitativa, realizado no período de agosto a outubro de 2014, com 10 mães de recém-nascidos pré-termo (RNPT) que se encontravam internados na Maternidade Escola Assis Chateaubriand (MEAC), Fortaleza-Brasil, e que haviam feito o contato pele a pele por meio do Método Canguru durante a internação na UTIN. Coletaramse os dados por entrevista semiestruturada, direcionados por questões norteadoras. Para tratamento dos dados, utilizou-se análise de conteúdo, sendo estabelecidas quatro categorias: "O vínculo e o apego", "A competência materna", "O medo da perda do bebê" e "A importância da equipe multidisciplinar". Resultados: O Método Canguru é uma prática segura e prazerosa para mães e familiares, além de propiciar vantagens sociais e psicoafetivas que se encontram no imaginário da institucionalização do método e na experiência das mães quando adequadamente apoiadas. Pode-se evidenciar significados dos sentimentos maternos de insegurança em decorrência do primeiro contato físico com o filho hospitalizado. No tocante a avaliação de sua prática clínica, este vem proporcionando melhor desenvolvimento do neonato e uma diminuição do tempo de internação hospitalar. Conclusão: O estudo apresenta relevância, pois a visão da percepção materna no que concerne este método faz com que este se firme como prática obrigatória em maternidades, tendo em vista seus benefícios para mãe e neonato.
\end{abstract}

Descritores: Método Canguru; Recém-Nascido; Unidades de Terapia Intensiva Neonatal.

\section{ABSTRACT}

Objective: To investigate the maternal perception of the experience in the first phase of the Kangaroo Mother Care Method in the Neonatal Intensive Care Unit (NICU). Methods: Descriptive, exploratory and qualitative study, conducted in the period from August to October 2014, with 10 mothers of newborn preterm (NP) infants, who were admitted to the Maternity School Assis Chateaubriand (MEAC) in Fortaleza, Brazil, and had received skin-to-skin contact through the Kangaroo Care Method during hospitalization in the NICU. Data was collected by semi-structured interview, directed by guiding questions. Content analysis was used for processing the data, being established four categories: "The bond and the attachment", "Maternal competence", "The fear of losing the baby" and "The importance of the multidisciplinary team". Results: The Kangaroo Care Method is a safe and pleasurable practice for mothers and relatives, in addition to providing social and psychoaffective benefits, found in the imagery of the method institutionalization and in the mothers' experience when properly supported. The meanings of the maternal feelings of apprehension as a result of the first physical contact with the hospitalized child can be evidenced. Regarding the evaluation of its clinical practice, this method has provided better development of the newborn infant and a reduction in hospital stay. Conclusion: The study shows relevance, since the evidence of the maternal perception of this method supports its establishment as a mandatory practice in maternity hospitals, in view of the benefits to the mother and the neonate.

Descriptors: Kangaroo-Mother Care Method; Newborn; Neonatal Intensive Care Unit.

\author{
Natália Paz Nunes ${ }^{(1)}$ \\ Úrsula Maria Lima Pessoa ${ }^{(1)}$ \\ Daniela Gardano Bucharles \\ Mont'Alverne ${ }^{(1)}$ \\ Fabiane Elpídio de Sá ${ }^{(1)}$ \\ Elisete Mendes Carvalho ${ }^{(1)}$
}

1) Universidade Federal do Ceará - UFC -
Fortaleza (CE) - Brasil
Recebido em: 02/04/2015

Revisado em: 22/06/2015

Aceito em: 04/09/2015 


\section{RESUMEN}

Objetivo: Conocer la percepción materna sobre la vivencia de la primera faseletapa del Método Canguro de la Unidad de Cuidados Intensivos Neonatal (UTIN). Métodos: Estudio descriptivo, de carácter exploratorio y naturaleza cualitativa realizado entre agosto y octubre de 2014 con 10 madres de recién nacidos pretermino (RNPT) que habian ingresado en la Maternidad Escuela Assis Chateaubriand (MEAC), FortalezaBrasil, las cuales habian tenido el contacto piel con piel a través del Método Canguro durante el periodo en la UTIN. Se recogió datos a través de la entrevista semi-estructurada orientados por cuestiones norteadoras. Se utilizó el Análisis de Contenido para el tratamiento de los datos del cual se estableció cuatro categorías: "El vínculo y el apego", "La competencia materna", "El miedo de perder el bebé" y "La importancia del equipo multidisciplinario". Resultados: El Método Canguro es una práctica segura y placentera para madres y familiares además de proporcionar ventajas a nivel social y psicoafectivo de la imaginación de la institucionalización del método y de la experiencia de las madres con el apoyo adecuado. Se puede evidenciar significados de los sentimientos maternos de inseguridad decurrente del primer contacto físico con el hijo ingresado. Respecto la evaluación de su práctica clínica lo mismo ha proporcionado mejor desarrollo del neonato y la disminución del tiempo de ingreso hospitalario. Conclusión: El estudio es relevante puesto que la visión de la percepción materna sobre este método le caracteriza como una práctica obligatoria de las maternidades por sus beneficios para la madre y el neonato.

Descriptores: Método Madre-Canguro; Recién Nacido; Unidades de Cuidado Intensivo Neonatal.

\section{INTRODUÇÃO}

A gravidez é um dos momentos mais críticos na formação das ligações afetivas entre a mãe e seu futuro bebê. No entanto, o nascimento de um bebê pré-termo representa para os pais uma situação nova, que pode comprometer o processo de vinculação ${ }^{(1)}$. Um dos métodos que favorece o fortalecimento do vínculo mãe-filho é o Método Canguru $(\mathrm{MC})^{(2,3)}$.

O MC consiste em uma tecnologia de assistência neonatal que implica no contato pele a pele precoce entre a mãe e o recém-nascido de baixo peso, de forma crescente, pelo tempo que ambos entenderem ser prazeroso e suficiente, permitindo uma maior participação dos pais no cuidado a seu recém-nascido ${ }^{(4,5)}$. O bebê é, em geral, colocado em posição supina, semidespido, entre os seios da mãe, na posição de rã ${ }^{(6)}$.

Foi originalmente desenvolvido em 1979, na cidade de Bogotá, e sua utilização se justificava pela falta de incubadoras, nas quais muitas vezes havia a necessidade de acomodar dois ou mais recém-nascidos ${ }^{(7)}$, e pelo alto índice de mortalidade nas maternidades colombianas ${ }^{(8)}$.

No Brasil, o MC difundiu-se rapidamente a partir de 1990. A norma brasileira determina que o MC deve ser aplicado em três etapas distintas, iniciando nas Unidades de Terapia Intensiva Neonatal (UTIN) e Unidades de Cuidados Intermediários (UCIN), passando às Unidades de Cuidado Intermediário Neonatal Canguru (UCINCa) (ou alojamento conjunto canguru) e, após a alta hospitalar, nos ambulatórios de seguimento (Follow up) ${ }^{(9)}$.

A primeira etapa inicia-se no pré-natal de alto-risco, seguido da internação do recém-nascido na UTIN. Nesse período, mãe e família devem ser orientados quanto às condições da criança, ressaltando os benefícios e a importância do MC. Na segunda etapa, o recém-nascido, após estabilização das condições clínicas, é transferido para a enfermaria canguru, onde ficará acompanhado de sua mãe, que assumirá a posição canguru pelo maior tempo possível, o que permite aumentar a proximidade física e comunicação entre mãe e bebê e o empoderamento materno. A terceira etapa começa quando o bebê recebe alta hospitalar e caracteriza-se pelo acompanhamento do bebê e da família no ambulatório e/ou domicílio até atingir o peso de 2.500 gramas. Após alcançar esse peso, o acompanhamento deve seguir as normas de crescimento e desenvolvimento do Ministério da Saúde ${ }^{(10)}$.

A promoção do cuidado materno emancipatório ao bebê prematuro deve fazer parte da práxis da equipe multidisciplinar no cuidado ao neonato. Ao apropriar-se dos códigos de comunicação da equipe, a mãe do prematuro habilita-se, da sua forma, para poder participar das decisões sobre as condutas terapêuticas direcionadas a seu filho. Assim, ao mesmo tempo em que o empoderamento materno causa certa estranheza e desconforto na equipe, a mãe redefine seu espaço na unidade neonatal. Uma vez que troca a imagem de fragilidade para uma posição mais assertiva em relação ao filho, a mãe passa a assumir seu lugar, capacitando-se a maternar seu filho, estimulando a interação. $\mathrm{O} \mathrm{MC}$ estimula, portanto, um novo pensar na equipe e proporciona maior autonomia materna ${ }^{(11)}$.

As vantagens desse método, já conhecidas e estudadas, são: aumentar o vínculo mãe-filho, evitar longos períodos sem estimulação sensorial, favorecer o desenvolvimento neurocomportamental (pois oferece estímulos olfatórios, auditivos, tácteis, térmicos e proprioceptivos ${ }^{(11)}$ ), estimular o aleitamento materno, aumentar a competência e confiança dos pais no manuseio do seu filho, proporcionar melhor controle térmico, melhorar o relacionamento da família com a equipe de saúde, diminuir os riscos de infecção cruzada e hospitalar, reduzir o número de abandono desses bebês, contribuir para o apego entre mãe/filho ${ }^{(12)}$, diminuir o tempo de permanência hospitalar e promover efeito analgésico ${ }^{(13-15)}$. 
Considerando que o MC representa uma estratégia fundamental para a otimização da assistência humanizada ao recém-nascido de baixo peso, à sua mãe e aos outros familiares, questiona-se qual a percepção de mães acerca da vivência na primeira etapa do Método Canguru na Unidade de Terapia Intensiva Neonatal (UTIN).

Assim, este estudo teve por objetivo conhecer a percepção materna acerca da vivência na primeira etapa do Método Canguru na Unidade de Terapia Intensiva Neonatal (UTIN).

Diante desse contexto, este estudo se justifica pela importância de se conhecer essa autonomia proporcionada à mãe no cuidado e pelos benefícios advindos dessa transformação junto ao filho prematuro.

\section{MÉTODOS}

O estudo teve inserção no enfoque descritivo de natureza qualitativa, realizado na Maternidade Escola Assis Chateaubriand (MEAC), que oferece o Programa de Assistência Humanizada ao Recém-Nascido de Baixo Peso - Projeto Canguru, em Fortaleza-CE, Brasil.

Pesquisa realizada no período de agosto a outubro de 2014, com 10 mães de recém-nascidos pré-termo (RNPT) que se encontravam internados e que haviam feito $o$ contato pele a pele por meio da posição canguru durante internação na UTIN. Considerando que as pesquisas do tipo qualitativas dispensam plenamente a quantidade definida de pessoas a serem entrevistadas, por tal aspecto depender da saturação teórica dos dados a partir da convergência dos achados ao objetivo proposto no estudo ${ }^{(14)}$, o número de sujeitos participantes da pesquisa não foi previamente estabelecido.

Coletaram-se os dados por entrevista semiestruturada, realizada com uso de gravador e diário de campo. Foi composta por duas etapas: a primeira é constituída de dados sociodemográficos (idade, estado civil, religião, nível de escolaridade, renda familiar) e dados relacionados aos recém-nascidos (sexo, idade gestacional, Apgar, tipo de suporte ventilatório ou oxigenioterapia); e a segunda etapa é composta por questões norteadoras com base nos objetivos propostos nesse estudo: 1) Porque aderiu ao método mãe canguru?; 2) Você já conhecia o método mãe canguru?; 3) Qual a importância desse método para você?; 4) Qual importância você considera que a participação no método mãe canguru irá acarretar para o seu bebê?; 5) Como você se sente participando do método mãe canguru em Unidade de Terapia Intensiva Neonatal?; 6) O que é ter um bebê prematuro?; e 7) Como se relaciona com a equipe de cuidados?

Identificaram-se as mães através dos códigos M01 a M10, conforme ordem de realização das entrevistas, respeitando a sua integridade intelectual, social e cultural.
Realizaram-se as entrevistas em uma sala localizada ao lado da UTIN, em um ambiente silencioso, com pequeno trânsito de pessoas. As mães dos recém-nascidos pré-termo que tinham feito a primeira etapa do $\mathrm{MC}$ foram abordadas pelas fisioterapeutas do serviço, as quais relataram o objetivo do estudo e perguntaram sobre o interesse das mães em participar da pesquisa.

Os dados foram tratados pela técnica de análise categorial temática ${ }^{(16)}$, conforme os passos recomendados. Efetuou-se a transcrição das entrevistas na íntegra. A seguir, ocorreram leituras sucessivas, com vistas à exploração do material obtido e recorte do texto em unidades de registro. Formularam-se as seguintes categorias temáticas: "O vínculo e o apego", "A competência materna", "O medo da perda do bebê" e "A importância da equipe multidisciplinar". A análise dos conteúdos respaldou-se na literatura pertinente ao tema.

Após esclarecimentos das mães quanto à pesquisa e sua aceitação em participar do estudo, houve a assinatura do termo de consentimento livre e esclarecido, com respeito às questões éticas e estabelecido através da Resolução n. 466/2012 do Conselho Nacional de Saúde, sendo a pesquisa aprovada pelo Comitê de Ética em Pesquisa da Maternidade Escola Assis Chateaubriand, sob o número 657.292.

\section{RESULTADOS E DISCUSSÃO}

A seguir, serão apresentados os dados sociodemográficos das mães entrevistadas e os dados relacionados aos recémnascidos, para em seguida serem apresentadas as categorias temáticas que emergiram do estudo.

Ao se analisar a faixa etária das mães envolvidas no estudo, constatou-se que três das mães apresentavam idade entre 15 e 25 anos. Cinco delas tinham entre 26 e 35 anos, e duas tinham idade entre 36 e 40 anos. Quanto ao estado civil das mães entrevistadas, quatro eram casadas e cinco, solteiras. Sobre a religião, sete eram católicas e três, evangélicas. Com relação ao nível de escolaridade, apurouse que uma das mães cursava o ensino fundamental; seis, o ensino médio; e três tinham curso superior completo. A renda familiar apresentou-se com uma das mães possuindo um salário mínimo como fonte de renda, sete das mães ganhavam de dois a três a salários mínimos, uma recebia de quatro a seis salários e as outras, acima de 10 salários mínimos.

Quanto aos dados clínicos dos RNPT envolvidos na pesquisa, constatou-se que sete eram do sexo masculino e três, do sexo feminino, com idade gestacional variando entre 27 semanas e 2 dias até 35 semanas, e idade corrigida estabelecida, até o dia da coleta dos dados, variando de 30 semanas e 1 dia a 39 semanas e 2 dias. Com relação ao peso no momento do nascimento, foi observado que um 
foi classificado como sendo de baixo peso $(<2500 \mathrm{~g})$ e sete possuíam muito baixo peso $(<1500 \mathrm{~g})$; um foi classificado como sendo de extremo baixo peso $(<1000 \mathrm{~g})$ e um, como ultrabaixo peso $(<750 \mathrm{~g})$. O boletim de Apgar no $1^{\circ}$ minuto do nascimento variou entre 2 e 9 , e no $5^{\circ}$ minuto variou entre 7 e 9. Foram coletados dados referentes ao tipo de suporte (ventilatório ou oxigenioterapia) utilizado no dia em que a mãe realizou o MC, sendo constatado que seis dos bebês se encontravam em ar ambiente, dois em pressão positiva contínua nas vias aéreas (CPAP) e dois em cateter nasal.

\section{O vínculo e o apego}

Esta categoria evidencia que a proximidade com o filho prematuro favorece a troca de afetividade e o estabelecimento do vínculo entre a mãe e o seu filho. Neste sentido, a posição canguru contribui com o exercício da maternidade, fazendo com que a puérpera possa vivenciar uma experiência sensorial mais direta com o filho, além de potencializar o seu papel de cuidadora, impactando desta forma sobre os sentimentos negativos oriundos dos primeiros dias de internação do RNPT na UTIN ${ }^{(17)}$.

A posição canguru aumenta o contato pele a pele entre mãe e filho, transmite carinho, calor e cria condições para o fortalecimento e estabelecimento do vínculo e do apego. Na percepção das puérperas, o primeiro contato com o filho através da posição canguru seria uma forma de contribuir com o retorno para seu ambiente doméstico, pois, ao retirarem o filho da incubadora e fornecerem o calor de seu corpo, poderiam acelerar a alta hospitalar ${ }^{(17)}$.

Dentro dessa temática, emergiram as seguintes falas:

Mulher, eu acho que, por ele ter esse contato com a mãe, que ele perdeu. Então a gente vai aprendendo novamente a ter aquele contatozinho de novo. Ele me sentir, eu sentir ele. (M01)

Porque o ambiente da incubadora é assim: eles ficam soltos, não têm o aconchego. Eles saem assim da barriga, de uma hora pra outra, e já ficam assim pra viver sozinho. (M04)

Eu tinha vontade de realmente pegar meu filho, porque eu só via ele na incubadora, então era a chance que eu tinha de ter ele próximo a mim. (M02)

Porque, na realidade, era pra ele ainda está no ventre, né? E ali (MC) é como se ele estivesse, eu vejo assim. (M06)

Proporcionar aos pais a oportunidade de visualizar e tocar a criança após o nascimento é extremamente útil para iniciar o vínculo afetivo, apego e, por consequência, favorecer o desenvolvimento ${ }^{(18)}$.
Como observado, a separação entre mãe e filho ao nascer causa danos, uma vez que a relação de apego é abalada e comprometida. Enquanto a mãe fica insegura e ansiosa por não poder cuidar do seu filho, a criança sente falta da segurança e do apego a ela transmitidos pela mãe durante a gravide ${ }^{(4,18)}$.

O relacionamento afetivo entre mãe e filho é um fator de instinto que influencia o desenvolvimento da identidade materna, sendo relacionado com a realização do papel de mãe, que busca proporcionar amparo físico e psicológico. A proximidade com o filho prematuro favorece a troca de afetividade e o estabelecimento do vínculo ${ }^{(6)}$.

\section{A competência materna}

Esta categoria versa sobre os benefícios do MC para as mães e se refere ao aumento de competência e da confiança maternas. Nesse sentido, o conceito de autoeficácia ${ }^{(19)}$, definido como a crença que a pessoa possui sobre sua habilidade de desempenhar, de forma bem sucedida, um determinado comportamento, pode também trazer contribuições à compreensão de como as mães se sentem diante das tarefas que compõem o cuidado de seu bebêt(20).

Ficar próxima ao bebê, participar de seus cuidados, amamentá-lo, saber que a equipe estará disponível ao seu filho, ajudar as outras mães tornando-se útil, aprender a lidar com os riscos da prematuridade reconhecendo as especificidades de seu bebê e superando suas dificuldades são modos de enfrentamento utilizados pelas mães para lidar com as emoções e sentimentos decorrentes da relação mãe e filho ${ }^{(6)}$.

Dentro dessa temática, emergiram as seguintes falas:

Eu me sinto útil. (M06)

Super-mãe, me acho. (M07)

Eu me sinto a "top", né? (M10)

Diversos autores apontam que o MC proporciona maior aquisição, por parte dos pais, de competência e confiança no manuseio de seu filho após a alta ${ }^{(10)}$.

Devido aos diversos sentimentos que a mãe apresenta de insegurança, medo, angústia e tristeza por ver seu filho prematuro envolto em um ambiente que não é a sua barriga, sem o acolhimento e o aconchego necessários para o seu desenvolvimento, ela muitas vezes se sente culpada por ele ter nascido antes do período determinado. Para as mães, o MC é uma forma delas se redimirem dessa culpa, fazendo com que elas possam contribuir para que seu bebê tenha alta da UTIN. No estudo, independentemente da faixa etária, todas as mães demonstraram sentimentos de preocupação, segurança, satisfação e de se sentirem úteis por estarem participando com seus bebês no MC. 


\section{O medo da perda do bebê}

A categoria em questão trata do medo da perda do bebê. A prematuridade, com seus riscos e consequências, tem um significado importante para os pais. A situação frágil do prematuro, que simbolicamente indica a presença de riscos para a sua sobrevivência, para o seu crescimento e desenvolvimento, sinalizou aos pais a necessidade de estar junto dele, de cuidar dele e de acompanhar a sua evolução pelo $\mathrm{MC}^{(18,21)}$.

Tanto para a criança como para os pais a hospitalização é vista como uma situação crítica e delicada. Durante a internação, vários fatores adversos estão presentes, como as mudanças psicológicas, o ambiente físico, a separação do binômio mãe-filho, entre outros. A visão de um bebê extremamente doente, cercado de cuidados e aparelhos, pode ser muito dolorosa para os pais, e certamente influenciará na qualidade do contato inicial. Assim, o medo da perda iminente e do desconhecido provavelmente transformará um momento de alegria em dúvidas e incertezas sobre o futuro próximo $^{(22)}$.

O medo da perda dos seus filhos foi um relato observado em todas as mães entrevistadas, demonstrando sentimentos de medo e pavor ao pensarem que, em cada procedimento, o uso de aparelhos respiratórios ou uma doença adquirida durante o período de internação na UTIN possa ser um risco de vida ao seu bebê. Outro sentimento presente foi o de insegurança, relacionada ao ato de cuidar do seu filho, pequeno e fragilizado, ao ser dada a alta hospitalar. Tal aspecto pode favorecer a rápida adoção do método pelas mães, visto que este viabiliza o primeiro momento para estarem em contato e poderem iniciar o cuidado de seu filho.

Esse sentimento é expresso pelas mães, como constatamos nas seguintes falas:

Mulher, no inicio é desesperador, sabe? (M01)

Muitas dúvidas, muito medo. O primeiro medo, o primeiro medo, é dele não conseguir sobreviver. Tem aquele receio em segundo plano, que é de ir pra casa, ao mesmo tempo que eu tenho muita vontade dele ir pra casa, mas que ele vá somente quando ele conseguir sobreviver no mundo aí. (M02)

Requer mais da gente. A gente tem que se dedicar mais. (M06)

A gente tem que ter todo o cuidado com eles, né? Tem que ter um cuidado redobrado. (M09)

A prematuridade é uma surpresa e é vista pelas mães como um risco de morte para seus filhos, trazendo o medo de não voltar para casa com seu filho tão sonhado e planejado. O momento da alta é temido pelos pais, mesmo que tenham tido a oportunidade de cuidar do filho, existe receio de que algo aconteça no $\operatorname{lar}^{(23)}$.

\section{A importância da equipe multidisciplinar}

Esta categoria trata do apoio à mãe, que sofre nesse momento e por isso necessita constantemente de informações, as quais devem ser consideradas como relevantes pelos profissionais, pois os problemas vivenciados podem interferir na flexibilidade e na espontaneidade das relações com a equipe de saúde. Muitas vezes, devido à falta de informação, as mães são dominadas por sentimentos de desconfiança, desespero, medo e incompreensão em relação ao quadro clínico do bebê. Esses fatores, associados, podem gerar nas mães um profundo sofrimento, acrescido do afastamento da UTIN e, consequentemente, do bebê, porque elas esperam receber atenção e informações fidedignas com um mínimo de clareza, ou seja, uma comunicação efetiva ${ }^{(4)}$.

O acolhimento, a interação e a comunicação da equipe com os pais desempenham papel fundamental para que as experiências emocionais desse período sejam melhor elaboradas e o sofrimento dos pais, minimizados ${ }^{(6)}$.

O relato das mães de sentirem-se acolhidas, de terem informações sobre o estado de saúde dos seus bebês e dos cuidados impostos pela participação da equipe multidisciplinar de modo geral demonstra a influência positiva que é ter uma equipe voltada para o cuidado inicialmente do bebê e, no segundo momento, ao atendimento psicológico das mães, sempre com a finalidade de tornar a mãe participativa e ativa na vivência durante o período de hospitalização do neonato.

Dentro dessa temática, emergiram as falas a seguir:

São muito cuidadosas as auxiliares, as enfermeiras. São muito atenciosas. Tudo o que a gente pergunta elas respondem. Estão sempre ali, prontas pra ajudar. (M04)

Aqui são todos muito atenciosos. Todos: a médica, as enfermeiras, as técnicas, as fisioterapeutas. (M02)

Eles estão direto olhando, direto cuidando. Então, quanto mais, melhor. (M06)

Por isso são importantes a informação correta e o diálogo entre a equipe de saúde e a família, para minimizar o temor sentido pelas mães nesse momento de fragilidade ${ }^{(20)}$. Segundo pesquisadores, a promoção desse cuidado facilita o vínculo mãe-filho, pois quando a mãe participante é acolhida por uma equipe de profissionais sensibilizados em humanizar o cuidado, verifica-se maior interação desta com seu filho, com a equipe e com a instituição ${ }^{(24)}$.

\section{CONSIDERAÇÕES FINAIS}

A análise da percepção materna acerca da vivência na primeira etapa do MC na UTIN envolve aspectos fortemente relacionados aos sentimentos e emoções dessas mães ao terem o primeiro contato pele a pele com seus filhos, que, 
apesar de um curto período de tempo, torna possível a formação e o fortalecimento do vínculo materno.

Ao encontrar as quatro categorias a partir das falas das mães - "O vínculo e o apego", "A competência materna", "O medo da perda do bebê" e "A importância da equipe multidisciplinar" -, o estudo corroborou com os achados da literatura. Apesar de serem encontradas essas quatro categorias, as mais marcantes e que demonstraram maior sentimento para a percepção materna na primeira etapa foram o início da formação do vínculo a partir do primeiro contato e o medo da perda de seu filho, envolvido em incertezas advindas da prematuridade de tê-lo novamente nos braços.

A realização deste estudo tem apresentado uma relevância teórica, clínica e social. Com relação ao aspecto social, pode evidenciar significados dos sentimentos maternos em decorrência do primeiro contato físico com o filho hospitalizado. No tocante à avaliação de sua prática clínica, esta vem proporcionando melhor desenvolvimento do neonato, ocasionando uma diminuição do tempo de internação hospitalar, e relevância teórica, pois a visão da percepção materna no que concerne a esse método faz com que ele se firme como prática obrigatória em hospitais, tendo em vista seus benefícios para a mãe e o neonato.

\section{REFERÊNCIAS}

1. Schmidt KT, Sassá AH, Veronez M, Higarashi IH, Marcon SS. A Primeira visita ao filho internado na unidade de terapia intensiva neonatal: percepção dos pais. Esc Anna Nery Rev Enferm. 2012;16(1):73-81.

2. Oliveira MC, Locks MOH, Girondi JBR, Costa R. Método canguru: percepção das mães que vivenciam a segunda etapa. Rev Pesqui Cuid Fundam. 2015;7(3):2939-48.

3. Menezes MAS, Garcia DC, Melo EV, Cipolotti R. Recém-nascidos prematuros assistidos pelo Método Canguru: avaliação de uma coorte do nascimento aos seis meses. Rev Paul Pediatr. 2014;32(2):171-7.

4. Eleutério FRR, Rolim KMC, Campos ACS, Frota MA, Oliveira MMC. O imaginário das mães sobre a vivência no método mãe-canguru. Ciênc Cuid Saúde. 2008;7(4):439-46.

5. Gontijo TL. Avaliação da implantação do cuidado humanizado aos recém-nascidos com baixo peso: método canguru. J Pediatr (Rio de J). 2010;86(1):33-39

6. Sá FE, Sá RC, Pinheiro LMF, Callou FEO. Relações interpessoais entre os profissionais e as mães de prematuros da unidade canguru. Rev Bras Promoç Saúde. 2010;23(2):144-9.

7. Souto DC, Jager ME, Pereira AS, Dias ACG. Método canguru e aleitamento materno: uma revisão integrativa da literatura nacional. Rev Ciência \& Saúde. 2014;7(1):35-46.

8. Lamy Filho F, Silva AAM, Lamy ZC, Gomes MASM, Moreira MEL. Avaliação dos resultados neonatais do método canguru no Brasil. J Pediatr (Rio de J) 2008;84(5):428-35.

9. Silva JR, Thome CR, Abreu RM. Método mãe canguru nos hospitais / maternidades públicos de Salvador e atuação dos profissionais da saúde na segunda etapa do método. Rev CEFAC. 2011;13(3):522-33.

10. Gontijo TL, Xavier CC, Freitas MIF. Avaliação da implantação do Método Canguru por gestores, profissionais e mães de recém-nascidos. Cad Saúde Pública. 2012;28(5):935-44.

11. Araújo BBM, Rodrigues BMRD, Pacheco STA. A promoção do cuidado materno ao neonato prematuro: a perspectiva da educação problematizadora em saúde. Rev Enferm UERJ. 2015;23(1):128-31.

12. Azevedo VMGO, David RB, Xavier CC. Cuidado mãe canguru em recém-nascidos pré-termo sob suporte ventilatório: avaliação dos estados comportamentais. Rev Bras Saúde Matern. Infant. 2011;11(2):133-8.

13. Silva ARE, Gracia PN, Guariglia DA. Método canguru e os benefícios para o recém-nascido. Rev Hórus. 2013;7(2):1-11.

14. Kerr LRFSL, Kendall C. A pesquisa qualitativa em saúde. Rev RENE. 2013;14(6):1061-3.

15. Bezerra YCP, Nóbrega LP, Nunes RMV, Costa TS, Medeiros RC. Método mãe canguru: uma revisão integrativa da literatura. Fiep Bulletin. 2014;84:1-7.

16. Bardin L. Análise de conteúdo. Lisboa: Edições 70 Persona; 2010.

17. Santos LM, Morais RA, Miranda JOF, Santana RCB, Oliveira VM, Nery FS. Percepção materna sobre o contato pele a pele com o prematuro através da posição canguru. Rev Pesqui Cuid Fundam. 2013;5(1):350414.

18. Costa R, Heck GMM, Lucca HC, Santos SV. Da incubadora para o colinho: o discurso materno sobre a vivência do método canguru. Rev Enferm Atenção Saúde. 2014;3(2):41-53. 
19. Bandura A. Self Efficacy Toward and Unifying theory of behavior change. Psychol Rev. 1977;84(2):191-215.

20. Spehar MC. Mães de bebês prematuros no Método Canguru: aspectos psicossociais, enfrentamento e autoeficácia [tese]. Brasília: Universidade de Brasília; 2013.

21. Ramalho MAM, Kochla KRA, Nascimento MEB, Peterlini O. A mãe vivenciando o risco de vida do recémnascido prematuro na Unidade de terapia Intensiva Neonatal. Rev Soc Bras Enferm Ped. 2010;10(1):7-14.

22. Maia FA, Azevedo VMGO, Gontijo FO. Os efeitos da posição canguru em resposta aos procedimentos dolorosos em recém-nascidos pré-termo: uma revisão da literatura. Rev Bras Ter Intensiva. 2011;23(3):3703.

23. Lucci, MA, Alvarenga MC, Infante AM, Freire, ACIF. Profissionais de enfermagem e suas representações sociais sobre o método mãe canguru. In: V Congreso Internacional de Investigación y Práctica Profesional en Psicología XX Jornadas de Investigación Noveno Encuentro de Investigadores en Psicología del MERCOSUR; 2013; Buenos Aires, Argentina. Buenos Aires: Acta Academica; p. 150-3. Disponível em: http://www.aacademica.org/000-054/578.pdf.

24. Costa R, Klock P, Borck M, Custódio Z, Barcelos M. Interdisciplinaridade na atenção humanizada ao recémnascido de baixo peso em um centro de referência nacional do método canguru. Holos. 2015;31(3):40414.

\section{Endereço para correspondência: \\ Natália Paz Nunes \\ Rua Sigefredo Pinheiro 545, Apt 404 \\ Bairro: Fátima \\ CEP: 60415-160 - Fortaleza - CE - Brasil \\ E-mail: nataliapaznunes@gmail.com}

